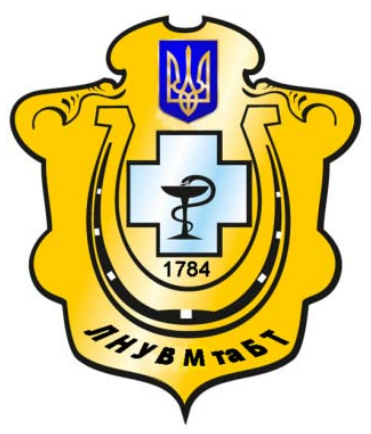

Науковий вісник Львівського національного університету ветеринарної медицини та біотехнологій імені С.3. Гжицького

Scientific Messenger of Lviv National University of Veterinary Medicine and Biotechnologies named after S.Z. Gzhytskyj

doi:10.15421/nvlvet7508

ISSN 2519-268X print

ISSN 2518-1327 online

$\underline{\text { http://nvlvet.com.ua/ }}$

УДК 531.42

\title{
Міркування щодо визначення маси атомів (іонів) кристалічної речовини
}

\author{
Я.І. Федишин ${ }^{1}$, Д.І. Вадець ${ }^{2}$ \\ fedyshyn.yaroslav@gmail.com
${ }^{I}$ Львівський національний університет ветеринарної медицини та біотехнологій імені С.3. Гюсицького, вул. Пекарська, 50, м. Львів, 79010, Украӥна;
${ }^{2}$ Начіональний університет водного господарства та природокористування, вул. Соборна, 11, м. Рівне, 33028, Украӥна

\begin{abstract}
Розглядається важливість числового значення маси гіпотетичного атома (іона) кристалу, через посередність якої розраховуються числові значення інших фізичних характеристик. Зокрема йдеться про визначення рентгенівськоі характеристичної температури Дебая або середньоквадратичного динамічного зміщення атомів від положення рівноваги при тепловому коливальному русі. B статті наводяться приклади знаходження атомних мас у кристалах типу $\mathrm{NaCl}$, CsCl, у твердих розчинах типу $\mathrm{Cu}$ - Ni або $\mathrm{Fe}$ - Ni та більш складних структурах типу $\mathrm{CaB}_{6}$ ma UB $B_{12}$.

Автори статті приводять математичні співвідношення розрахунків величин середніх та зведених атомних мас для двоатомних і трьохатомних структур кубічної сингонії. Зокрема, для двохатомних структур типу $\mathrm{NaCl} \mathrm{ma} \mathrm{CsCl} \mathrm{середня}$ атомна маса $A_{c p}=\frac{A_{N a}+A_{C l}}{2}$, де $A_{N a}$ i $A_{C l}$ - атомні маси натрія і хлора в молекулах відповідно. Спочатку розраховуються атомні маси у відносних одинииях мас, а потім, при необхідності, можна знайти усереднені маси гіпотетичних атомів. Для структур, які складаються із атомів малої різниці мас пропонується використовувати середні маси гіпотетичних атомів. Для структур із великою різницею мас атомів пропонується використовувати зведені маси при дослідженні акустичної вітки коливного спектру особливо в області температур, щуо нижчі за характеристичну.

При визначенні амплітуд коливань кожного сорту атомів у речовині слід використовувати метод розділення цих коливань. В иъьму випадку відпадає необхідність розрахунку атомних мас, оскільки визначається показник степеня температурного множення $M$ Дебая: $M=\frac{8}{3} \pi^{2} \overline{U^{2}} \frac{\sin ^{2} \vartheta}{\lambda^{2}}$, де $\overline{U^{2}}-$ середньоквадратичне зміщення атома від положення рівноваги, $\vartheta$ - кут дифракції, $\lambda$-довжина хвилі рентгенівських променів.

Ключові слова: середня маса, зведена маса, характеристична температура Дебая, середньоквадратичне динамічне зміщення атомів, гіпотетичний атом, амплітуда теплових коливань атомів, молярна маса, атомна маса.
\end{abstract}

\section{Рассуждение относительно определения массы атомов (ионов) кристаллической вещества}

\author{
Я.И. Федишин ${ }^{1}$, Д.И. Вадец ${ }^{2}$ \\ fedyshyn.yaroslav@gmail.com \\ ${ }^{1}$ Львовский национальный университет ветеринарной медицины и биотехнологий им. С.3. Гљсицкого, \\ ул. Пекарская, 50, м. Львов 79010, Украина; \\ ${ }^{2}$ Национальный университет водного хозяйства и природопользования, \\ вул. Соборная, 11, м. Ровно, 33028, Украина
}

Рассматривается важность числового значения массы гипотетического атома(иона) кристалла, через посредственность которой рассчитываются числовые значения других физических характеристик. В частности речь

Citation:

Fedyshyn, Y.I., Vadets, D.I. (2017). Considerations to determine the mass of atoms (ions) of crystalline substance. Scientific Messenger LNUVMBT named after S.Z. Gzhytskyj, 19(75), 40-44. 
идет об определении рентгеновской характеристической температуры Дебая или среднеквадратического динамического смещуения атомов от положения равновесия при тепловом колебательном движении.

В статье приводятся примеры нахождения атомных масс в кристаллах типа NaCl, CsCl, в твердых растворах типа

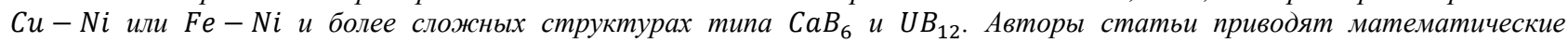
соотношения расчетов величин средних и приведенных атомных масс для двухатомных и трехатомных структур кубической сингонии. В частности, для двухатомных структур типа NaCl и CsCl средняя атомная масса маса $A_{\text {ср }}=$ $\frac{A_{N a}+A_{C l}}{2}$, где $A_{N a}$ i $A_{C l}$ - атомные массы натрия и хлора в молекулах соответственно. Сначала рассчитываются атомные массы в относительных единицах масс, а затем, при необходимости, можно найти усредненные массы гипотетических атомов. Для структур, которые состоят из атомов с небольшой разницей масс предлагается использовать средние массы гипотетических атомов. Для структур с большой разницей масс атомов предлагается использовать приведеннье массы при исследовании акустической ветви колебательного спектра особенно в области температур, ниже характеристической. При определении амплитуд колебаний каждого сорта атомов в веществе следует использовать метод разделения этих колебаний. В этом случае отпадает необходимость расчета атомных масс, поскольку

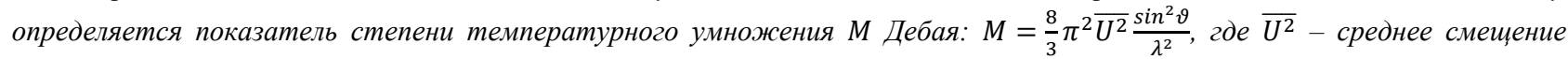
атома от положения равновесия, $\vartheta$ - угол дифракции, $\lambda$ - длина волны рентгеновских лучей.

Ключевые слова: средняя масса, приведенная масса, характеристическая температура Дебая, среднеквадратическое динамическое смещение атомов, гипотетический атом, амплитуда тепловых колебаний атомов, молярная масса, атомная Macca.

\title{
Considerations to determine the mass of atoms (ions) of crystalline substance
}

\author{
Y.I. Fedyshyn ${ }^{1}$, D.I. Vadets ${ }^{2}$ \\ fedyshyn.yaroslav@gmail.com \\ ${ }^{1}$ Lviv National University of Veterinary Medicine and Biotechnologies named after S.Z. Gzhytskyi, \\ Pekarska Str., 50, Lviv, 79010, Ukraine; \\ ${ }^{2}$ National university of water resources and environmental Scirnces, \\ Soborna Str., 11, Rivne, 33028, Ukraine
}

We consider the importance of numerical value of the mass of the hypothetical atom (ion) crystal, which through the medium of of that mass are calculated numerical values of other physical characteristics. In particular it is the determination of the characteristic X-ray Debye temperature or medium quadratic dynamic displacement of atoms from the equilibrium position the thermal vibration of their movement. It is often calculated the average or taken numerical value of the mass of the hypothetical atom of matter. In its turn the magnitude of this value depends on how it calculate.

The article provides examples of the atomic masses of crystals type $\mathrm{NaCl}, \mathrm{CsCl}$, in solids type $\mathrm{Cu}-\mathrm{Ni}$ or $\mathrm{Fe}-\mathrm{Ni}$, and more complex structures such $\mathrm{CaB}_{6}$ and $U B_{12}$.

Authors of the article bring mathematical equations calculating the value of and consolidated atomic masses for diatomic and triatomic structure of cubic system. In particular, for diatomic structures such $\mathrm{NaCl}$ and $\mathrm{CsCl}$ an average atomic mass, where $A_{N a} i$ $A_{C l}$-atomic mass of sodium and chloride molecules, respectively.

In previous studies the authors by radiographic high temperature methods investigated the physical properties of the aforementioned alloys, ionic crystals and iso-type structures $\mathrm{CaB}_{6}\left(\mathrm{MeB}_{6}\right)$ and $U B_{12}\left(\mathrm{MeB} \mathrm{B}_{12}\right)$. In this case they had to count, to some extent, the average atomic mass. The calculation results of averages and consolidated atomic masses in the article for hexaboride and dodecaboride given only for extreme masses of molecules. First atomic mass are calculated in relative units of mass, and then, if necessary, can be found inside the mass of the hypothetical atoms. In the tables is presented part of such calculations. Typically the average atomic mass is larger than the resulted mass. For izostructures consisting of atoms of small mass difference it is proposed to use average mass of the hypothetical atoms. For structures with large difference of atoms mass it is proposed to use the reduced mass at research of acoustic branches of vibration spectrum, especially in the temperature that is below the characteristic temperature.

In this case, there is no need calculate the atomic mass, because it was determined the exponent of temperature multiplying $M$ Deby: $M=\frac{8}{3} \pi^{2} \overline{U^{2}} \frac{\sin ^{2} \vartheta}{\lambda^{2}}$, where $\overline{U^{2}}-$ mean-square displacement of an atom from equilibrium position, $\vartheta-$ the angle of diffraction, $\lambda$ - the wavelength of $X$-rays.

Key words: average mass, taken numerical value mass, characteristic Debye temperature, the mean dynamic displacement of atoms, hypothetical atom, the amplitude of the thermal vibrations of the atoms, the molar mass, the atomic mass.

\section{Вступ}

При дослідженні властивостей різних кристалічних речовин важливим параметром є маси їх атомів.

За внутрішньою структурою розрізняють прості речовини, які складаються 3 атомів одного сорту та складні речовини з атомів різних сортів. Відносно значень мас атомів особливо це важливо при дослідженні коливного руху, та виборі методу дослідження.

Існують різні методи вивчення властивостей кристалічних речовин. Кожен із методів дослідження доповнює один одного, крім того, деякі 3 них $\epsilon$ не замінимі. Серед таких $є$ рентгенографічний метод, особливо при високо температурному рентгенографуванні. Цей метод дає можливість визначити значення температурного множника зменшення інтенсивності рентгенівських дифракційних 
максимумів ехр(-2M) має вигляд (Dzhejns, 1950; UmanUmanskij, 1967; Kriwohlaz, 1967):

$$
\exp (-2 \mathrm{M})=\exp \left\{-\frac{12 L^{2} T}{m k \theta^{2}}\left[\frac{1}{4} \frac{\theta}{T}+\Phi\left(\frac{\theta}{T}\right)\right] \frac{\sin ^{2} \vartheta}{x^{2}}\right\}
$$

де $h$ - стала Планка, $\mathrm{m}$ - маса атома, $k$ - стала Больцмана, $\theta$ - характеристична дебаївська температура, Т - абсолютна (термодинамічна) температура, $\vartheta-$ кут інтерференції рентгенівських променів, $\Phi\left(\frac{\theta}{T}\right)$ - функція Дебая.

Знаючи характеристичну температуру $\theta$ можна визначити середнє повне зміщення $u^{2}$ атомів від положення рівноваги:

$$
\begin{aligned}
& u^{2}=\frac{9 h^{2}}{4 \Pi^{2} m k \theta}\left[\frac{T}{\theta} \Phi\left(\frac{\theta}{T}\right)+\frac{1}{4}\right] \\
& =\frac{9 h^{2} T}{4 \pi^{2} m k \theta^{2}}\left[\frac{1}{4} \frac{\theta}{T}+\Phi\left(\frac{\theta}{T}\right)\right]
\end{aligned}
$$

Правда, оскільки

$$
\mathrm{M}=\frac{8}{3} \pi^{2} u^{2} \frac{\sin ^{2} \vartheta}{\lambda^{2}}
$$

То $u^{2}$ можна визначити опосередковано через $\mathrm{M}$ та $\vartheta$.

Теорія твердих тіл Дебая розвинена для простих однотонних кристалічних речовин, в яких враховуються зв'язані коливання атомів з частотами від нуля до $\vartheta_{\max }$. Згідно цієї теорії передбачається, що хвилі всіх довжин, частот і напрямків поширюються 3 однаковими швидкостями. Це означає що реальний кристал замінюється моделлю ізотропного середовища . Цим кристалам відповідають речовини простої кубічної структури, які складаються не лише 3 атомів одного сорту, але й кристали типу $\mathrm{NaCl}$.

Не вдаючись у деталі поправок по визначенню $\theta$ та $u^{2}$, за рентгенівськими данними можна визначити числові значення низки характеристик кристалічних речовин зокрема коефіцієнта $\beta$ об'ємного розширення, постійну Грюнайзена $\gamma$, максимальну частоту коливань атомів, оцінити значення ангармонічних коефіцієнтів $f, g, h, \quad$ в розкладі потенціальної енергії коливань атомів, модуль Юнга $\mathrm{E}$, універсальну міру ангармонізму $\mathrm{n} \gamma \beta=-\frac{d \ln \theta}{d T}$ коливань атомів у кристалі, швидкість звуку тощо. Однак, для цього потрібно, наприклад, у співвідношенні (1) і (2) підставити значення маси атомів досліджуваної речовини.

\section{Матеріал і методи дослідження}

Для кристалів 3 атомами одного сорту проблем відносно величини їх мас не існує. Подібна ситуація і при дослідженні твердих кристалічних розчинів (сплавів) 3 майже однаковими масами атомів, наприклад у сплавах системи $\mathrm{Cu}-\mathrm{Ni}$ чи $\mathrm{Fe}-\mathrm{Ni}$ або у простих речовинах $з$ незначними домішками.

Частіше всього у формули (1) і (2) підставляють середні маси атомів, або зведені їх маси.

3 роз'вязку рівнянь руху різних атомів (наприклад в моделі ланцюжка) впливає зведена маса гіпотетичного атома.

У випадку хімічних сполук з ковалентним, іонним i металічним зв'язками при невеликих розмірах кристалічної комірки і при помірних температурах комірка коливається як ціле. Це означає, що атоми практично не змінюються один відносно іншого. Такі коливання атомів відповідають акустичній вітці. Тому у вираз для температурного множника інтенсивності дифракційних максимумів рентгенівських променів слід підставити усереднену масу гіпотетичного атома

$$
\frac{1}{m_{3 \mathrm{~B} .}}=\frac{C_{1}}{m_{1}}+\frac{C_{2}}{m_{2}},
$$

Де $m_{1}$ i $m_{2}$ - маси атомів компонентів речовин i $C_{1}$ та $C_{2}$ їх атомні долі.

Очевидно приведена атомна маса замінюється величиною:

$$
\frac{1}{\mathrm{~A}_{\text {зв. }}}=\frac{C_{1}}{\mathrm{~A}_{1}}+\frac{C_{2}}{\mathrm{~A}_{2}},
$$

Де $A_{3 в}, A_{1}$ i $A_{2}$ зведена атомна маса компонентів речовини та їх атомні долі відповідно.

У випадку структур типу $\mathrm{NaCl}$ та $C s C l$ :

$$
\begin{gathered}
A_{C}=\frac{A_{N a}+A_{C l}}{2} \\
\frac{1}{\mathrm{~A}_{3 \mathrm{~B}}}=\frac{C_{N a}}{\mathrm{~A}_{N a}}+\frac{C_{C l}}{\mathrm{~A}_{C l}}
\end{gathered}
$$

У випадку сплавів типу $\mathrm{Cu}-\mathrm{Ni}$ :

$$
A_{c}=\frac{C_{1} \mathrm{~A}_{1}+C_{2} \mathrm{~A}_{2}}{2},
$$

Де $C_{1}$ та $C_{2}$ - атомні процентні долі $\mathrm{Cu}$ і $N i$ в сплаві та $\mathrm{A}_{1}$ і $\mathrm{A}_{2}$ - їх атомні маси відповідно;

$$
\frac{1}{\mathrm{~A}_{3 \mathrm{~B}}}=\frac{C_{1}}{\mathrm{~A}_{1}}+\frac{C_{2}}{\mathrm{~A}_{2}} .
$$

У випадку твердих розчинів, наприклад, $\mathrm{KCl}-$ $\mathrm{KBr}$ іони хлору і брому розташовані серед аніонних вакансій. Тому середню і приведену атомні маси в сплаві можна розрахувати за співвідношенням:

$$
\begin{gathered}
A_{c .}=\frac{\mathrm{P}_{1} \mathrm{~A}_{1}+\mathrm{P}_{2} \mathrm{~A}_{2}}{2}, \quad(10) \\
\frac{1}{\mathrm{~A}_{\text {зв.ат.маси }}}=\mathrm{P}_{1}\left(\frac{0,5}{\mathrm{~A}_{\mathrm{K}}}+\frac{0,5}{\mathrm{~A}_{\mathrm{Cl}}}\right)+\left(\frac{0,5}{\mathrm{~A}_{\mathrm{K}}}+\frac{0,5}{\mathrm{~A}_{\mathrm{B} r}}\right),
\end{gathered}
$$

де $\mathrm{P}_{1}$ i $\mathrm{P}_{2}$ та $\mathrm{A}_{1}$ i $\mathrm{A}_{2}$ - молярні долі і молярні маси $\mathrm{KCl}$ та $K B r$ відповідно. В (11) $\mathrm{P}_{1}$ і $\mathrm{P}_{2}$ - ті що й в (10), 0,5 - атомні долі $\mathrm{K}, \mathrm{Cl}, \mathrm{Br}$, у відповідних молекулах. Числові значення атомних мас взяті із фізичного довідника.

\section{Результати та їх обговорення}

В таблицях 1, 2, 3, подані значення середніх та зведених атомних мас у відповідних молекулах та сплавах.

Таблиия 1

Значення середніх та зведених атомних мас у відповідних молекулах

\begin{tabular}{|c|c|c|}
\hline Речовина & $A_{C \text {.ат.маси }}$ & $A_{\text {3в.ат.маси }}$ \\
\hline $\mathrm{NaCl}$ & 29,221 & 27,892 \\
\hline$K C l$ & 37,275 & 37,186 \\
\hline$K B r$ & 59,501 & 52,505 \\
\hline$K I$ & 83,001 & 59,779 \\
\hline$C s C l$ & 84,179 & 55,975 \\
\hline
\end{tabular}


Середні та зведені атомні маси у сплавах системи $\mathrm{KCl}-\mathrm{KBr}$.

\begin{tabular}{|c|c|c|}
\hline Речовина & $A_{\text {с.ат.маси }}$ & $A_{\text {зв.ат.маси }}$ \\
\hline 100 мол. \% $\mathrm{KCl}$ & 37,275 & 37,186 \\
\hline 90 мол. $\% \mathrm{KCl}-10$ мол. $\% \mathrm{KBr}$ & 39,498 & 38,300 \\
\hline 80 мол. $\% \mathrm{KCl}-20$ мол. $\% \mathrm{KBr}$ & 41,721 & 39,491 \\
\hline 70 мол. $\% \mathrm{KCl}-30$ мол. $\% \mathrm{KBr}$ & 43,943 & 40,754 \\
\hline 60 мол. $\% \mathrm{KCl}-40$ мол. $\% \mathrm{KBr}$ & 46,166 & 42,100 \\
\hline 50 мол. $\% \mathrm{KCl}-50$ мол. $\% \mathrm{KBr}$ & 48,388 & 43,538 \\
\hline 40 мол. $\% \mathrm{KCl}-60$ мол. $\% \mathrm{KBr}$ & 50,611 & 45,077 \\
\hline 30 мол. $\% \mathrm{KCl}-70$ мол. $\% \mathrm{KBr}$ & 52,833 & 46,730 \\
\hline 20 мол. $\% \mathrm{KCl}-80$ мол. $\% \mathrm{KBr}$ & 55,056 & 48,509 \\
\hline 10 мол. $\% \mathrm{KCl}-90$ мол. $\% \mathrm{KBr}$ & 57,279 & 50,428 \\
\hline 100 мол. \% $\mathrm{KBr}$ & 59,501 & 52,505 \\
\hline
\end{tabular}

Середні та зведені атомні маси у сплавах системи $\mathrm{Cu}-\mathrm{Ni}$

Таблицяя 3

\begin{tabular}{|c|c|c|}
\hline Речовина & $A_{\text {с.ат.маси }}$ & $A_{\text {зв.ат.маси }}$ \\
\hline $100 \mathrm{fn.} \% \mathrm{Cu}$ & 63,546 & 63,546 \\
\hline 90 ат. $\% \mathrm{Cu}-10$ ат. $\% \mathrm{Ni}$ & 63,062 & 63,026 \\
\hline 80 ат. $\% \mathrm{Cu}-20$ ат. $\% \mathrm{Ni}$ & 62,578 & 62,516 \\
\hline 70 ат. $\% \mathrm{Cu}-30$ aт. $\% \mathrm{Ni}$ & 62,095 & 62,013 \\
\hline 60 ат. $\% \mathrm{Cu}-40$ aт. $\% \mathrm{Ni}$ & 61,611 & 61,519 \\
\hline 50 ат. $\% \mathrm{Cu}-50$ aт. $\% \mathrm{Ni}$ & 61,128 & 61,032 \\
\hline 40 ат. $\% \mathrm{Cu}-60$ ат. $\% \mathrm{Ni}$ & 60,644 & 60,553 \\
\hline 30 ат. $\% \mathrm{Cu}-70$ ат. $\% \mathrm{Ni}$ & 60,160 & 60,081 \\
\hline 20 ат. $\% \mathrm{Cu}-80$ aт. $\% \mathrm{Ni}$ & 59,677 & 59,617 \\
\hline 10 ат. $\% \mathrm{Cu}-90$ ат. $\% \mathrm{Ni}$ & 59,123 & 59,160 \\
\hline 100 ат. $\% \mathrm{Ni}$ & 58,710 & 58,710 \\
\hline
\end{tabular}

3 таблиць 1-2 видно, що середні і зведені атомні маси речовин, які складаються 3 хімічних елементів 3 атомними масами, що не далекі за величиною. Середні і зведені молярні та атомні маси речовин, які складаються з елементів 3 явно різними атомними масами також надто різні. Як правило, середні атомні маси більші від приведених мас $\left(A_{\text {с.ат.м. }}>A_{\text {зв.ат.м. }}\right)$.

Вище наведені приклади відносились до речовин 3 більш-менш простими кубічними кристалічними гратками, до яких застосовується теорія Дебая.

Однак, існують речовини кубічної сингонії, але зі складною будовою. До таких речовин відносяться, наприклад, гексабориди типу $\mathrm{CaB}_{6}$ i додекабориди типу $\mathrm{UB}_{12}$. Речовини типу $\mathrm{CaB}_{6}\left(\mathrm{MeB}_{6}-\right.$ метал бор шість) мають об'ємноцентровану кубічну (ОЦК) гратку, відносяться до просторової групи $\mathrm{O}_{h}^{1}-\mathrm{P}_{\mathrm{m} 3 \mathrm{~m}}$. Каркас із 6-ти атомами бору утворює октаедр, в пустотах між якими розміщені атоми металу. В елементарній кристалічній комірці знаходиться одна молекула $\mathrm{MeB}_{6}$ (Mirkin, 1961).

Речовини типу $\mathrm{UB}_{12}\left(\mathrm{MeB}_{12}\right)$ мають гранецентровану кубічну (ГЦК) кратку, кристали відносяться до просторової групи $\mathrm{O}_{h}^{5}-\mathrm{F}_{\mathrm{m} 3 \mathrm{~m}}$. Каркас із 12-ти атомами бору утворюють кубооктаедр, в пустотах між якими розміщені атоми металу. В елементарній комірці знаходить 4 молекули $\mathrm{MeB}_{12}$.

Гексабориди та додекабориди відносяться до тугоплавких речовин (Samsonow, 1975), тому їх властивості вивчають багато експериментаторів, які намагаються розширити межі застосування теорії Дебая.

Ми розрахували значення атомних мас великої групи гексаборидів і додекаборидів, навіть уявляючи ix за структурою типу $\mathrm{NaCl}$ та $\mathrm{CsCl}$, розглядаючи каркаси атомів бору як один гіпотетичний атом.

Для прикладу в таблиці 4 приведені розраховані атомні маси гіпотетичних атомів лише деяких (крайніх) за масами гексаборидів і додекаборидів.

Таблиия 4

Середні та приведені атомні маси гексаборидів і додекаборидів

\begin{tabular}{|c|c|c|c|c|}
\hline Речовина & $A_{\text {с.ат.маси }}$ & $A_{\text {зв.ат.маси }}$ & $\begin{array}{c}A_{\text {с.ат.маси }} \\
\text { в моделі } A B\end{array}$ & $\begin{array}{c}A_{\text {зв.ат.маси }} \\
\text { в моделі } A B\end{array}$ \\
\hline$C a B_{6}$ & 14,991 & 12,069 & 52,470 & 49,544 \\
\hline$T h B_{6}$ & 42,414 & 12,514 & 148,449 & 101,382 \\
\hline$N_{2} B_{12}$ & 14,494 & 11,534 & 94,210 & 80,825 \\
\hline$U B_{12}$ & 28,288 & 11,667 & 183,875 & 167,925 \\
\hline
\end{tabular}


Характерною особливістю середніх та зведених атомних мас $\epsilon$ їх невелике збільшення середніх і майже незмінні зведені атомні маси в реальних структуpax типу $\mathrm{CaB}_{6} \mathrm{i} \mathrm{UB}_{12}$. Тому для ізоструктур типу $\mathrm{MeB}_{6}$ i $\mathrm{MeB}_{12}$ при вивченні коливних рухів краще користуватись зведеними атомними масами.

Уявляти гексабориди і додекабориди структурою типу $A B(\mathrm{NaCl})$ не треба.

\section{Висновки}

Отже, у випадку простих кристалів кубічної сингонії з однотипними атомами проблем 3 атомними масами не існує. У випадку кристалів, які складаються 3 атомів 3 невеликою різницею мас, можна використовувати середні атомні маси. При вивченні властивостей кристалів типу $\mathrm{NaCl}, \mathrm{CsCl}$ слід використовувати як середні так і приведені маси гіпотетичних ато- мів у залежності від типу розрахунків інших фізичних величин.

При визначенні амплітуд теплових коливань атомів різних сортів треба використати рентгенографічний метод розділення цих коливань.

\section{Бібліографічні посилання}

Dzhejns, R.W. (1950). Opticheskie principy difrakcij rentgenovskih luchej. Moskwa (in Russian)

Umanskij, I.S. (1967). Rentgenohrafij metallow. Moskwa: Metallurgij (in Russian).

Kriwohlaz, M.A. (1967). Teorija rassejanija rentgenovskih luchej i teplovyh nejtronov real'nymi kristallami. «Nauka». Moskva: fizmat literatura (in Russian).

Mirkin, L.I. (1961). Spravochnik po rentgenostrukturnomu analizu polikristallov. Moskwa: Fizmatgiz (in Russian).

Стаття надійшла до редакиії 20.02.2017 